\title{
Análisis y evaluación de servicios públicos locales desde la perspectiva geográfica. Un estudio de caso
}

\section{Antonio Moreno Jiménez * \\ Consuelo Álvarez Vela * ${ }^{2}$}

\section{Introducción}

Una de las vías a través de las cuales el Estado actúa más eficazmente modificando el bienestar colectivo estriba en su papel de proveedor de servicios a la población. La satisfacción de un buen número de necesidades sociales está, total o parcialmente, supeditada a la gestión que órganos de la Administración, sobre todo municipal, llevan a cabo. Desde hace cierto tiempo la reflexión por parte de diversas disciplinas científicas acerca de los objetivos, procedimientos e implicaciones de la toma de decisiones públicas está suponiendo una revisión importante de dicho proceso y suscitando propuestas de cambio para mejorarlo, subsanando deficiencias y desajustes constatados.

Con la eclosión de las corrientes radicales en los años setenta, la Geografía, como disciplina interesada en el estudio de los resultados espaciales de la actuación de los agentes públicos y privados, abrió en su seno una línea de indagación acerca de los efectos de la acciones públicas sobre el bienestar, la eficiencia o la equiclad, haciéndose eco de una preocupación análoga en otras disciplinas (en especial la Economía y la Ciencia Política y de la Administración). Las aportaciones seminales de HaRver (1973) y MasSAM (1975), seguidas por las de SMITH (1977), BENNETT (1980), PINCH (1985), MASSAM (1993) y muchos otros, sirvieron para clarificar y fundamentar conceptualmente y prefigurar metodológicamente la relevancia del enfoque geográfico en el análisis de políticas públicas.
Uno de los conceptos claves que más difusión ha tenido entre las organizaciones, sobre todo públicas, es el de evaluación (vid., por ejemplo, Patton y Sawicki, 1986; Subirats, 1989; MonNier, 1992). Tanto en el horizonte, más dilatado temporalmente, que se avista con la planificación, como en el corto plazo, en el que discurren las labores de gestión, la pertinencia de realizar estudios de evaluación puede ser sustentada siempre por un buen punado de razones y en ello ha estribado su progresiva aceptación. En esencia, se trata de obtener, de forma rigurosa y sistemática, una cierta cantidad de información sobre la cuestión-problema para permitir la formación de un juicio u opinión que se suele proyectar, ulteriormente, en decisiones de tenor y alcance diversos, sean estratégicas, tácticas u operativas, según la distinción de GRIMSHAw (1994).

Dentro de las competencias ejercidas por el sector público que dan lugar a un conjunto de actividades y de gasto importantísimo se sitúa la provisión de servicios a la población, la cual, naturalmente, se está constituyendo en objeto prioritario de la acción evaluadora (BALLART, 1992). Sea cual fuere el nivel de las decisiones por parte de las diferentes instancias responsables de los mismos (desde el político, al técnico), es importante reconocer que las opciones y actuaciones adoptadas terminan, a la postre, por hacer o no realidad las virtualidades de una oferta local concreta. Calibrar la marcha y funcionalidad de unos servicios, es decir, evaluarlos, cobra pues su exacta dimensión como herramienta fundamental en la gestión (LANCASTER, 1990), bien para justificar su existencia y el gasto generado, bien para orientar decisiones de gestión (cambiar el rumbo, potenciar parcelas, corregir erro- 
res, etc.), bien para conocer y dimensionar sus efectos o resultados.

En este contexto se sitúa el foco de este trabajo en el cual, sin perjuicio de reconocer la amplia gama de aspectos reconocidos en la bibliografía como susceptibles de justificar una acción evaluadora, el acento se ha puesto en tres de ellos, los cuales, amén de contarse entre los habituales, posibilitarán subrayar la relevancia de la Geografía para analizar la actuación de ciertos servicios municipales. Tales son:
A) Medir la eficiencia de la oferta existente.
B) Examinar la distribución social de los beneficios del ser- vicio y precisar el perfil de los usuarios (beneficiarios).
C) Precisar la distribución espacial de esos beneficios.

Al objeto de concretar el alcance del trabajo ciertas acotaciones resultan procedentes. En primer lugar, debe tenerse presente que se trata de un estudio de carácter eminentemente empírico, de tal suerte que las consideraciones de tipo teórico irán ineludiblemente asociadas a una concreción real, tratando de mostrar la viabilidad y valor de los hallazgos. Ello introduce ciertas limitaciones en la extensión de la investigación, si bien el objetivo de ilustrar puede quedar satisfactoriamente alcanzado con el caso abordado. En segundo lugar, se trata de una aproximación eminentemente geográfica (o más exáctamente socio-espacial), por lo que, sin desdoro de otras perspectivas, se ha buscado enfatizar los aspectos y conclusiones obtenibles mediante dicho enfoque. En particular, se persigue también explotar una tecnología novedosa, la de los sistemas de información geográfica (SIG), en el desarrollo del estudio.

Una breve disgresión conviene esbozar respecto a este último punto. La idoneidad de los SIG en el terreño que aquí nos concierne se sustenta en su pertenencia a la reconocida categoría de los sistemas de información para la dirección y gestión, necesarios para viabilizar los procesos de planificación corporativa y estratégica en la administración pública, en general, y en cada uno de los servicios que gestiona (vid. BRYSON, 1992). Las posibilidades de los SIG para el análisis de políticas han sido postuladas genéricamenté por varios autores. CaLKins (1991, pág. 234) por ejemplo enunció al respecto tres tipos de usos de los SIG: 1) Determinar dónde y cuándo se requieren políticas públicas. 2) Apoyar a la formulación de políticas públicas. 3) Determinar el grado en que las políticas públicas tienen éxito y alcanzan los objetivos buscados. Por su parte, WORRal (1991, págs. 2:3) ha enumerado un amplio abanico de usos potenciales de los que merecen subrayarse los siguientes: 1) Mejor seguimiento de los cambios demográficos, sociales, económicos y ambientales del entorno; 2) Predicción más exacta de las necesidades cambiantes de servicios; 3) Determinación más precisa de las variaciones espaciales de la condiciones de vida, como base para las políticas sociales y asignación de recursos públicos lo- cales; 4) Identificación de mercados objetivo para promoción de servicios locales; 5) Planificación de servicios más efectiva y enfocada, mediante la determinación de los condicionantes de la demanda; 6) Mejora en la calidad de gestión de servicios al soportar aproximaciones más económicas y eficientes; 7) Mejora del proceso de formulación de políticas, mediante métodos más sensibles para la evaluación y análisis de políticas y programas. Y finalmente, Moreno (1993) ha resenado cómo las diversas fases del proceso de formulación de políticas públicas pueden ser soportadas mediante numerosas tareas de tipo analítico involucrando a los SIG. Sin que signifique sacralizar el poder de dicha tecnología, uno de los fines de este trabajo estribará, como se ha dicho antes, en proporcionar una ilustración asequible de sus posibilidades en aras de divulgarlas y valorarlas.

\section{El caso de estudio y los datos}

El objeto de estudio abordado, las bibliotecas, resulta bastante representativo de un tipo de servicios que, siendo habitual entre la oferta municipal, posee el carácter de equipamiento deseable para la población, es decir, que resulta claramente dispensador de "utilidades" y con prácticamente nulos efectos negativos (externalidades). Por su naturaleza se trata de un servicio con un acceso prácticamente gratuito y sin casi restricción del uso individual, a no ser el inherente a los requisitos mínimos de obtención del carnet de lector, por limitación horaria de la oferta o por congestión. Ello significa que la obtención de las utilidades ofrecidas en dichos puntos está asociada al uso de dichos servicios libremente y en la cuantía deseada por cada vecino. Un hecho obvio, pero de indudable trascendencia a los efectos geográficos, radica en que dicha oferta, al igual que la demanda, está localizada y que la satisfacción de la necesidad implica un desplazamiento de ésta hacia aquélla.

El municipio seleccionado para llevar a cabo el ensayo ha sido el de Alcobendas, una ciudad dentro del área metropolitana madrileña con unos 85.000 hab. en 1995. A efectos de obtener información sobre el servicio y su funcionamiento se llevó a cabo una encuesta doble: por un lado, a los responsables municipales del servicio, mediante un cuestionario que recogía extremos diversos de los recursos (instalaciones, personal, horarios, dotaciones, etc. $)^{3}$, por otro, a los usuarios, mediante una encuesta realizada los días 11-12 junio de 1990 con objeto de averiguar sus rasgos y las formas e intensidad de la utilización. No se adoptó en este caso muestreo alguno, encuestándose a la casi totalidad de los usuarios. Tras la depuración se obtuvieron un total de 653 cuestionarios válidos. La información fue tratada 
básicamente con dos herramientas informáticas: un programa estadístico y un sistema de información geográfica.

\section{En torno al problema de la medición del output de un servicio}

El intento de determinar de forma precisa los resultados o performance de un servicio público ha suscitado una notable bibliografía que ha puesto de relieve los matices y dificultades a los que hay que enfrentarse y las distintas formas de abordaje que el problema ofrece. Algunos autores se han inclinado por un enfoque más teórico o economicista (por ejemplo, MEYER, 1986 o BeNNETT, 1980), en tanto que otros han adoptado una aproximación más social, empírica o próxima a los resultados tangibles de cada servicio, postulando el uso de indicadores (por ejemplo MaSSAM, 1975; BarRIL Dosset, 1985). Al respecto conviene insistir en que el análisis de la distribución de bienes y servicios públicos resulta compleja ya que, como apuntó LINEBERRY (1977), existen siete problemas importantes: el registro de la información (disponibilidad de datos), la medición (problematismo por la elusividad de los aspectos a medir), la falacia de análisis parciales (sólo algunos aspectos del output), la falacia ecológica (tamaño y forma de la desagregación socio-espacial), el desigual grado en que los bienes (servicios) públicos son "puros" y el problema de las externalidades.

En este estudio se ha optado por una perspectiva que conjuga los indicadores técnicos y sociales, por resultar mucho más intuitiva y afín a los responsables locales del servicio, circunstancia que puede favorecer su entendimiento y adopción. Más aún, dado el tipo de servicio, para la medición se privilegiará una perspectiva individualista, es decir, simplificando los hechos, se trata de asimilar el output a las utilidades que en primera instancia y de forma fehaciente son detectables a nivel personal. Su medida sería registrable en tanto que se traduce en actos de uso o consumo. La simplificación, justo es decirlo, se manifiesta al menos en dos sentidos: de un lado, porque junto a las ventajas privadas, existen también en muchos casos ventajas colectivas no valoradas, y de otro porque, junto al receptor directo, pueden existir también otros beneficios indirectos sobre terceros, a veces muy relevantes.

Un ensayo de cuantificar el output a través de indicadores exige identificar las principales dimensiones o vectores sobre los que concretar la medición, de tal suerte que haga viables las comparaciones y la formación de juicios de valor. Al respecto podria sugerirse deslindar estos ejes:
- Una desagregación por tipo de beneficio/perjuicio.

- Una desagregación por equipamiento o instalación.

- Una desagregación por grupos sociodemográficos.

- Una desagregación espacial.

- Una desagregación temporal.

La especificación por tipo de beneficio, equipamiento y por grupos sociales atiende a las necesidades mínimas y más conspicuas de estos análisis, por cuanto hace posible por un lado el cotejo de resultados entre unos puntos de provisión y otros, mediante los oportunos indicadores de eficiencia/rentabilidad de los recursos, y por otro la detección de quiénes son los directamente beneficiados por dicha oferta, abriendo la vía al examen de los resultados desde consideraciones de justicia social por ejemplo (figura 1).

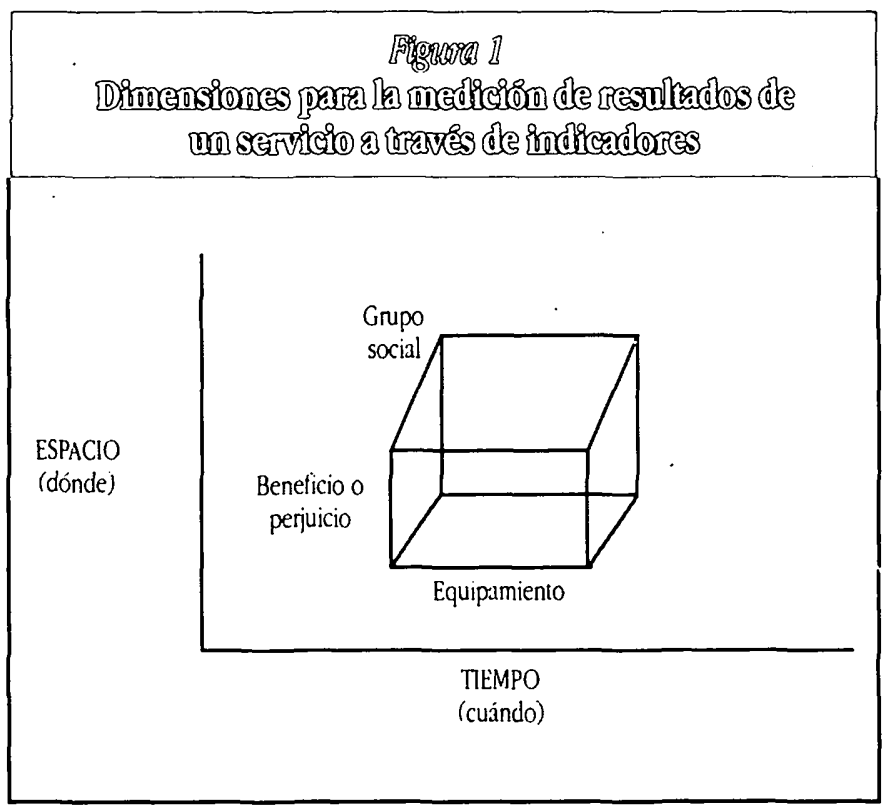

La importancia de la dimensión espacial en la medición del output (beneficios y perjuicios) ha sido quizá el punto más subrayado desde la Geografía por dos razones inexcusables. En primer lugar porque, como se evidenció en las discusiones sobre la teoría de los bienes públicos puros, el hecho de que la oferta de una inmensa mayoría de ellos esté localizada constituye un factor de "impurezai de indudable trascendencia analítica y política y, en segundo lugar, porque al estar igualmente localizada la población destinataria de dichos servicios, tal hecho condiciona de forma muy determinante el reparto social de las utilidades públicamente provistas. Dicho de forma más clara, ante la desigual distribución de los grupos sociales en el espacio, que se hace especialmente patente a escala local, esto es, dentro de la ciudad, la pregunta de cómo se distribuyen socialmente los beneficios/perjuicios de la actuación pública resulta incompleta. 
Las segregaciones intraurbanas o a otras escalas territoriales según status socio-económico, raza-etnia, religión, edad, etc., exigen tener en cuenta explícitamente esas variaciones para entender y valorar correctamente la apropiación social de las utilidades públicas que siempre se hacen en un contexto espacial concreto y condicionadas por él.

Finalmente, la especificación temporal nos recuerda la necesaria referenciación por períodos estándar y significativos para posibilitar tanto la medición, como para la ejecución del deseable seguimiento diacrónico de resultados, teniendo en cuenta tanto los cambios en la oferta, como en la demanda.

En sintesis, la clásica cuestión central a abordar se podría enunciar de dos maneras, según que el énfasis recayese en la oferta o en la demanda del servicio: A) ¿Qué equipamiento genera qué efectos (beneficios/perjuicios) entre qué receptores, dónde y cuándo? B) ¿Quién consigue qué beneficios/perjuicios de qué equipamiento, dónde y cuándo? En este contexto, el dónde tendría una doble lectura según que se referenciasen los hechos por la localización del equipamiento o de los beneficiarios (demanda). El cuándo podría, a su vez, dar lugar a interpretaciones también dobles según se confrontase con la disponibilidad horaria de la oferta o de la demanda para la ejecución del acto de servicio. En el marco de este estudio, dada la limitación temporal de los datos disponibles, se-omitirá un tratamiento del cuándo y, en lo atingente a los beneficios, se abordarán de forma sumaria por razones de espacio.

\section{Indicadores de eficiencia/rentabilidad de dotaciones para la evaluación}

El análisis centrado en los puntos de servicio se suele enfocar hacia la valoración de aspectos tales como los costes, la calidad, los resultados, la efectividad (consecución de objetivos) y eficacia, etc., de cada uno de ellos, en aras de calibrar los aciertos o errores en su funcionamiento. Una ejecución más ajustada de tàl examen comparativo suscita a menudo la conveniencia de tener en cuenta los recursos (inputs o insumos) aportados en cada establecimiento para, de este modo; arribar a medidas de eficiencia. En síntesis, interesa en general el cotejo sobre la base de cocientes entre resultados e insumos (vid. MORENo, 1987). Para el caso de "las bibliotecas diversos autores han -propuesto un amplio abanico de criterios de cualificación de la ofer- ta y el servicio (vid., por ejemplo, LANCASTER, 1988; WhITEHALl, 1992; Hendrikson, 1994; DuarTe Barrionuevo, 1995). A efectos de nuestros objetivos, podrían retenerse, como indicadores de recursos o inputs, los siguientes:

- Fondos bibliográficos (total y por categorías).

- Instalaciones disponibles (tamaño y tipos de salas)

- Mobiliario (puestos de trabajo o lectura).

- Personal de servicio (total, especializado y complementario).

- Horas de apertura (cuantía, distribución temporal).

- Gasto de funcionamiento (total, por capítuloș).

En lo concerniente a resultados (equiparables a menudo a utilidades), entre la rica gama de aspectos susceptible de ser medidos, una forma muy asequible estriba en utilizar datos derivados de alguna forma de registro contable de los actos de uso real o servicio prestado. En ciertos casos ello es fácil, debido a que la prestación o uso deja una huella documental (por ejemplo, muchos actos de la atención sanitaria, educación, el préstamo de libros, etc.), en otros, sin embargo, el nivel de registro es menor (como es el caso del acceso y utilización libre de las salas de bibliotecas para estudio o lectura) sin que medie un apunte por el personal responsable. Ello suscita la necesidad periódicamente, de completar los datos sobre el uso a base de encuestas, como aquí se ha realizado. En cualquier caso, entre la información susceptible de ser adoptada para tal fin podría sugerirse:

- Usuarios (magnitud total y por categorías socio-demográficas).

- Uso realizado (total y por categorías tales como préstamo, estudio en sala, consultas, etc.).

- Tiempo de utilización (total, distribución a lo largo de períodos significativos).

A título de ilustración en el cuadro 1 se presentan algunos indicadores del tipo expuesto, a efectos de posibilitar ese examen valorativo de los resultados de cada una de las bibliotecas municipales. Dentro de las limitaciones que afectan a una encuesta restringida a un solo día son perceptibles notables diferenciasi entre los distintos puntos de servicio en estos indicadores. Así, por ejemplo, la Biblioteca Central resulta destacada en lo concerniente a uso general (en asistencia y tiempo de estancia) y préstamo. La sita en la calle Pablo Serrano, la más pequeña y marginal, aparece con bajos valores habitualmente. El corolario para los responsables del servicio consiste en reflexionar acerca de las razones tanto de los buenos, como de los insuficientes o bajos rendimientos que algunos puntos de oferta muestran y en adoptar medidas para su eventual corrección. 


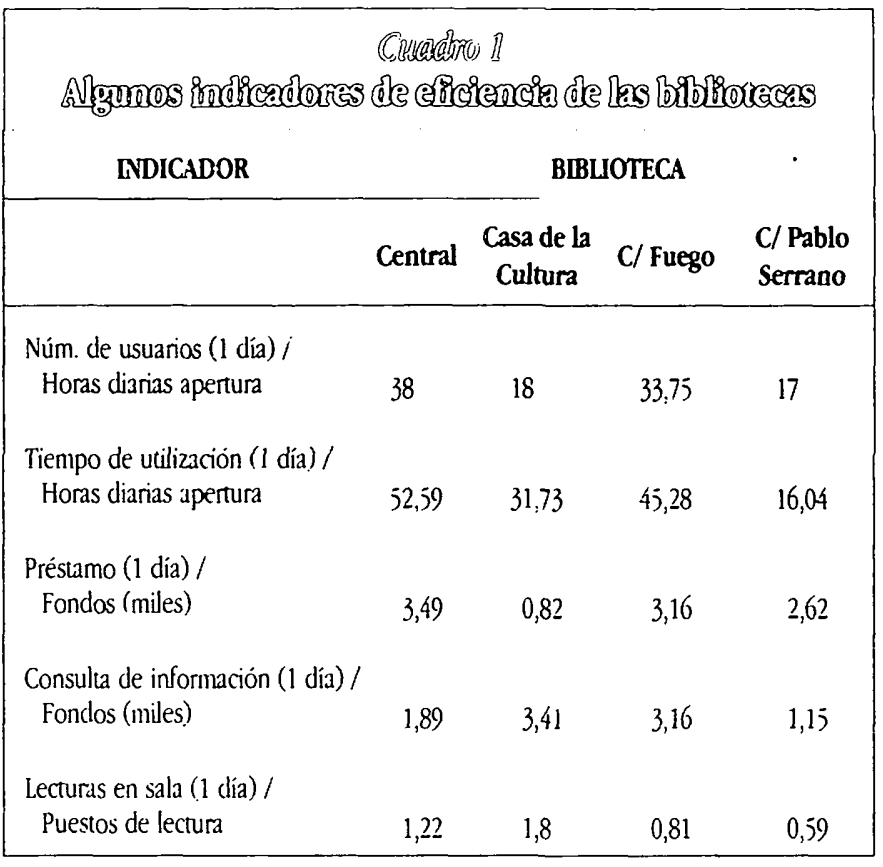

Fuente: Encuesta propia.

\section{La distribución socio-espacial de los beneficios y el geomarketing público}

ceptores directos serían una fuente primera para, a partir de información referente a los mismos, identificar esos beneficios.

Un componente informativo para dar respuesta a la preguntà que al final del apartado 3 se planteaba (quién consigue qué) $y$, por tanto, para aproximarse a esa medición, ha de centrarse naturalmente en los rasgos de los propios individuos. Tal decisión posee una doble virtualidad: por un lado, posibilita una expresión cuantitativa del beneficio a través de indicadores como la forma, extensión o magnitud del uso por parte de distintos grupos sociales, $y$, por otro, hace viable una determinación de los perfiles de la eclientelar, labor que forma parte de la aplicación de la perspectiva del marketing al sector público. Esta última iniciativa, postulada desde hace ya cierto tiempo por los especialistas en marketing (CROMPTON y LAMB, 1986; KOTLER y ANDREASEN, 1987; WalSh, Clarke y Stewart, 1989; Kotler y ROBERTO, 1992), ha sido recogida positivamente entre los expertos en gestión bibliotecaria, los cuales han ido revisando su aplicabilidad y metodología en varios trabajos programáticos (vid., por ejemplo, DelGado, 1993; OJlambo, 1994). La innovación más reciente en este terreno se ha derivado del entronque con la perspectiva geográfica y ha sido bautizada como geomarketing (Grimmeau y RoELANDTS, 1995). El acento radica ahora en considerar como sustantiva y crítica la faceta "territorialn. Aplicado al caso de los usuarios ello significa, no sólo identificar su composición y el uso que hacen, sino también y simultáneamente su extracción espacial, es decir, ubicarlos dentro del ámbito pertinente (dónde están, por ejemplo, sus domicilios). En los apartados siguientes se presenta de forma sintética, pero expresiva, la aplicación de las precedentes reflexiones al caso objeto de estudio.

\subsection{El perfil de los usuarios de las bibliotecas como indicador de los grupos sociales beneficiados}

La diferenciada oferta de servicios que cada establecimiento bibliotecario municipal realiza, junto con los patrones individuales de necesidades culturales y las condiciones de accesibilidad espacial desembocan en un uso socialmente selectivo de dicha oferta. La demanda expresada a través de una utilización significativa traduce de forma bastante exacta el grado de penetración de la oferta y entre qué grupos sociales. Un análisis pormenorizado debería centrarse en la conexión tipo de uso-rasgos de los usuarios con objeto de extraer la mejor información sobre quién usa qué y para qué (i.e., quién obtiene qué utilidad o beneficio) tanto para fines evaluadores, como para marketing público. En este trabajo, por economía de espacio, se realizará una visión más global y se expondrán sólamente los rasgos más destacados de los usuarios, prescindiendo de la desagregación por tipo de uso. La misma razón inhibe el desglose por áreas 
menores dentro del municipio, tarea ágilmente realizable mediante el concurso de los SIG.

Al respecto, en la encuesta se obtuvieron una serie de atributos personales de los visitantes, cuyo tratamiento informático arrojó los datos expresados en el cuadro 2. En aras de la simplicidad y legibilidad, en dicho cuadro se han retenido exclusivamente las magnitudes porcentuales (referidas al número de usuarios, bien total, bien de cada biblioteca) superiores a ciertos umbrales relevantes (tanto en términos absolutos, como relativos). Ello posibilita detectar fácilmente cómo la edad constituye un discriminador fundamental del uso para el conjunto del servicio (muy abundante entre los grupos de 10-19 años) y también para ciertas bibliotecas. Así, por ejemplo, la Central y la de la Casa de la Cultura, con oferta más cualificada, recogen porcentajes importantes de usuarios entre 20-24 y la de Pablo Serrano obtiene una fuerte penetración entre los pequeños de 5-9 años. Entre sexos se constata un cierto desequilibrio, necesitado de más indagación explicativa, en el sentido de una subrepresentación femenina. La conclusión es clara: el servicio se usa por un público abrumadoramente joven, rasgo que obviamente lleva emparejados otros atributos relevantes para la segmentación del mercado.

Así, en lo que respecta a situación ocupacional, el colectivo dominante es el estudiantil (más del 86 por ciento), rasgo que constituye un claro catalizador del consumo bibliotecario. El segundo grupo en importancia numérica, aunque a considerable distancia, es el formado por los que poseen un empleo o simultanean trabajo y estudio, los cuales además se canalizan hacia las dos bibliotecas más importantes ya mencionadas (Central y Casa de la Cultura). Otros segmentos de la clasificación ocupacional utilizada o no aparecen (caso de los jubilados) o apenas representan trazas (parados y amas de casa). De esto último resulta llamativo el hecho de que ciertos grupos que disponen de tiempo libre apenas se vean alcanzados" por esa oferta cultural. Ello puede constituir un motivo de reflexión acerca de los móviles de su exclusión y de las posibles medidas de los responsables culturales para extender entre ellos el uso y utilidades del servicio.

Dados los dos grupos de ocupación significativos que, como usuarios, se han detectado, resulta conveniente ahondar algo más en sus rasgos específicos. En el segmento de estudiantes, en conjunto la participación va disminuyendo a medida que se eleva el nivel educativo. Ello es muy patente en dos de las bibliotecas, si bien en las dos más importantes el esquema de usuarios cambia ostensiblemente: en la Centrat hay un equilibrio entre niños de EGB y universitarios, en la Casa de la Cultura predominan estos últimos. Dentro del segmento de no estudiantes se ha procedido a otras dos clasificaciones según profesión y nivel de instrucción. Las categorías emergentes, siempre dentro de cifras exiguas, son ciertas ocupaciones en el sector servi- cios (empleos de oficina o cuello blanco) y con nivel de instrucción medio o superior. En este sentido se evidencia que son aquellos grupos que han disfrutado de un mayor contacto con la educación o que realizan tareas relacionadas con la información sensu lato los más beneficiados, en tanto que los trabajadores de la fabricación, transporte, comercio, hostelería, etc., apenas presentan indicios. La valoración que rezuma de estos datos es simple: la propensión a consumir más bibliotecas es mayor a medida que el individuo está más cultivado y, paradójicamente, aquéllos que en teoría deberían aumentar su nivel de culura apenas se acercan a esos focos de difusión. He ahí un desafío para la política y gestión municipal de estos servicios.

\subsection{Distribución espacial de los beneficios: estudio descriptivo mediante un SIG}

El examen de los aspectos considerados en el apartado anterior cobra una nueva luz cuando se aplica la perspectiva geográfica, atenta siempre a referenciar cualquier hecho en el espacio. De esta forma, aporta una visión más rica àl introducir la desagregación territorial y permitir apreciar cómo se distribuyen los beneficios (el uso o los usuarios) por las distintas zonas del municipio. Al respecto, y de una manera concreta, surgen algunas preguntas sustantivas que orientan la indagación: ¿Dónde viven los usuarios, desde qué zonas de la ciudad brota la demanda o, dicho en términos indudablemente más adecuados para el gestor de servicios públicos y para los políticos locales, qué zonas se están beneficiando de los recursos puestos a disposición de los ciudadanos y financiados públicamente? El tradicional análisis cartográfico se ha visto potenciado mediante la aplicación de los SIG, los cuales permiten proveer una respuesta ágil y completa a esos interrogantes de una forma tanto visual, como numérica y para las particiones del espacio urbano que se estimen relevantes. Las posibilidades son tan amplias que tan sólo es factible esbozar y ejemplificar aquí con una corta cifra de los productos obtenibles y pertinentes para el análisis y la gestión de políticas de servicios locales.

En primer lugar, es posible, por ejemplo, construir y examinar en un mapa la localización de los domicilios de los usuarios ${ }^{4}$, bien de todas las bibliotecas (figura 2), bien de cada una de ellas por separado. Ello permite ya una "lectura" de diversos aspectos: qué zonas son las que más y menos aportan, cuál es el área de atracción de cada punto de servicio, etc. Nótese que el SIG, al gestionar la base de datos de atributos de cada usuario, permite conocer de forma instantánea los datos para cada uno de los puntos (usuarios) mediante la consulta oportuna (por ejemplo marcando sobre el punto con el pulsador). Este tipo de mapas tan minuciosos ofrecen indudables posibilidades para los gestores. 


\section{(Carcerchro) I}

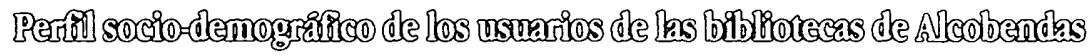

BIBLIOTECA

-...

Clase o grupo

Central (Barrio 6)

Casa de la Cultura

C/ Fuego

C/ Pablo Serrano

Total

Edad

$5-9$

10-14

15-19

20-24

- Indicados sólo intervalos con \% > a 5

Sexo

Varones

Mujeres

54,9

44,7

55,6

43,8

16,7

41,7

25,0

22,4

8,2
48,9

29,4

9.3

48,9

39,3

50,0

14,7

30,5

35,5

16,1

Situación

ocupacional

\section{Estudiante}

Con empleo

Estud. y empleo

84,5

6,2

4,6

80,6
10,4
4,9

97,7

92,6

86,2

53,3

54,4

54,5

- Indicadas sólo categorías con \% >a 4

ESTUDIANTES

Nivel de estudios

EGB

BUP o FP

34,6

25,0

Universitario

Otros

35,0

5,4

18,4

30,4

41,6

57,7

81,3

41,2

9,6

25,7

- Indicadas sólo categorías con \% > a 4

NO ESTUDLANTES

Profesión

Profesionales, técnicos, etc.

Pers. de serv, admón. y similares

Hostelería, serv. doméstico, protección y simil.

Industria, transpores, construcción y similares

Total (absoluto)

- Indicadas sólo categorías con frecuencia absoluta $\geq 5$

$\begin{array}{rrrr}24,0 & 26,1 & & 16,7 \\ 52,0 & & 28,2 \\ & 39,1 & & 12,8 \\ & & & 7,7 \\ 25 & 23 & 4 & 4 .\end{array}$

Nivel de instrucción

BUP y FP

Est. universitarios

No contesta
61.9

33,3
56,2

37,5
29,5

18,0

47,4

- Indicadas sólo categorias con frencuencia absoluta $\geq 5$

Fuente: Encuesta propia.

Nota: Las cifras del cuadro son porcentajes verticales, es decir; respecto al total de usuarios de cada biblioteca.

Sin embargo, el grado de detalle individual puede en ocasiones ser excesivo y representaciones visuales más sintéticas posibilitan una apreciación más pertinente para transmitirla, por ejemplo, a ciertos decisores. Al efecto, el recurso a mapas por zonas deviene muy oportuno. La figura 3 permite valorar la cuantía relativa de los usuarios de una de las bibliotecas respec- 


\section{2}

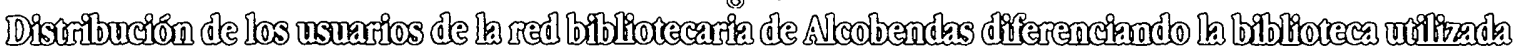

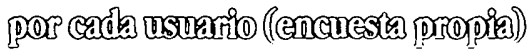
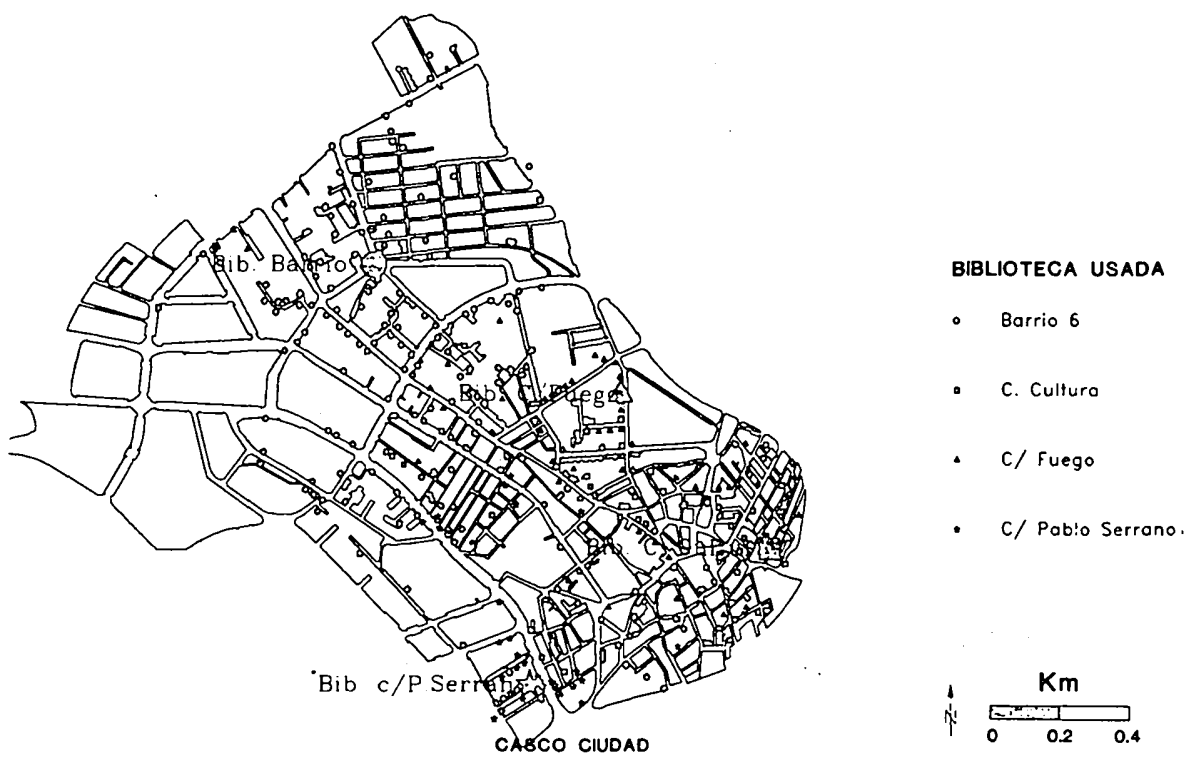

Fuente: Elaboración propia.

\section{Fitiona 3}

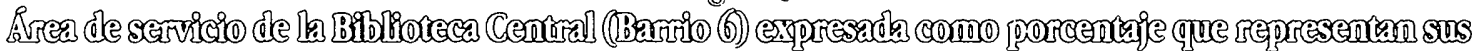

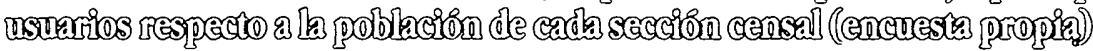

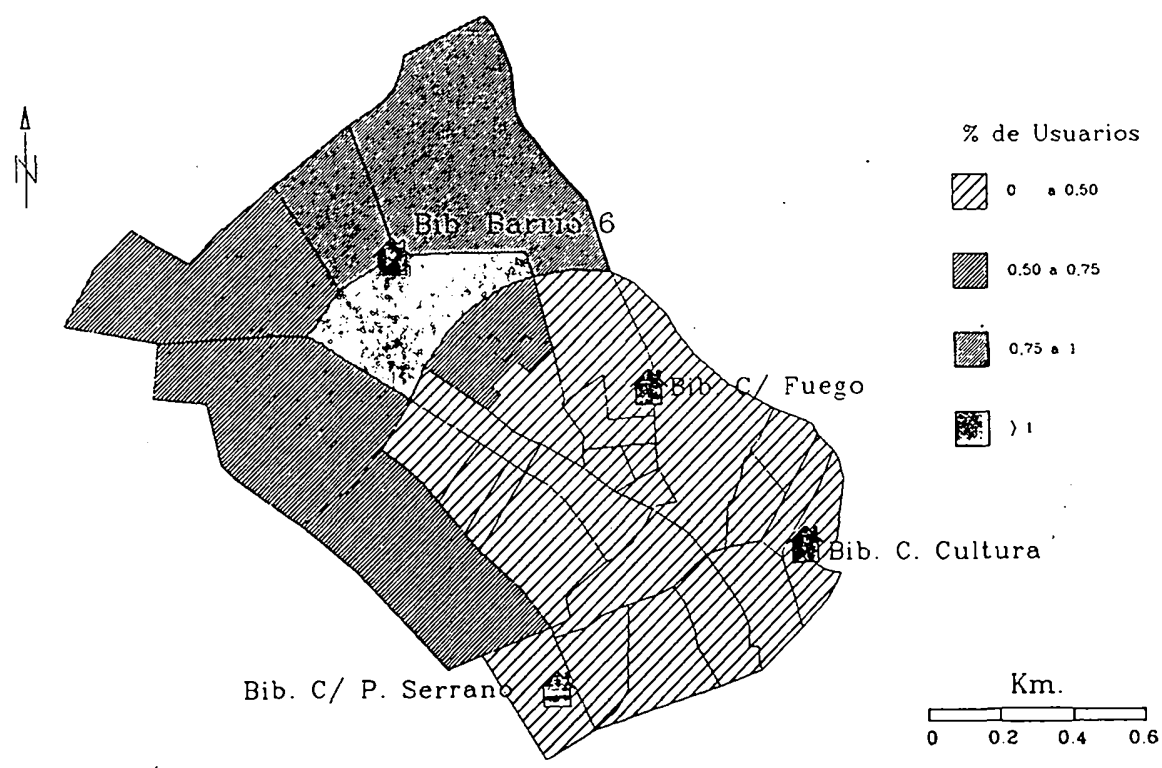

Fuente: Elaboración propia.

to al total de residentes en cada sección censal del casco urbano. Se percibe nítidamente cómo la zona de servicio de la misma, o lo que es lo mismo, la parte de la ciudad que se beneficia de tal equipamiento se sitúa al NW. La contraposición de dicha imagen con 


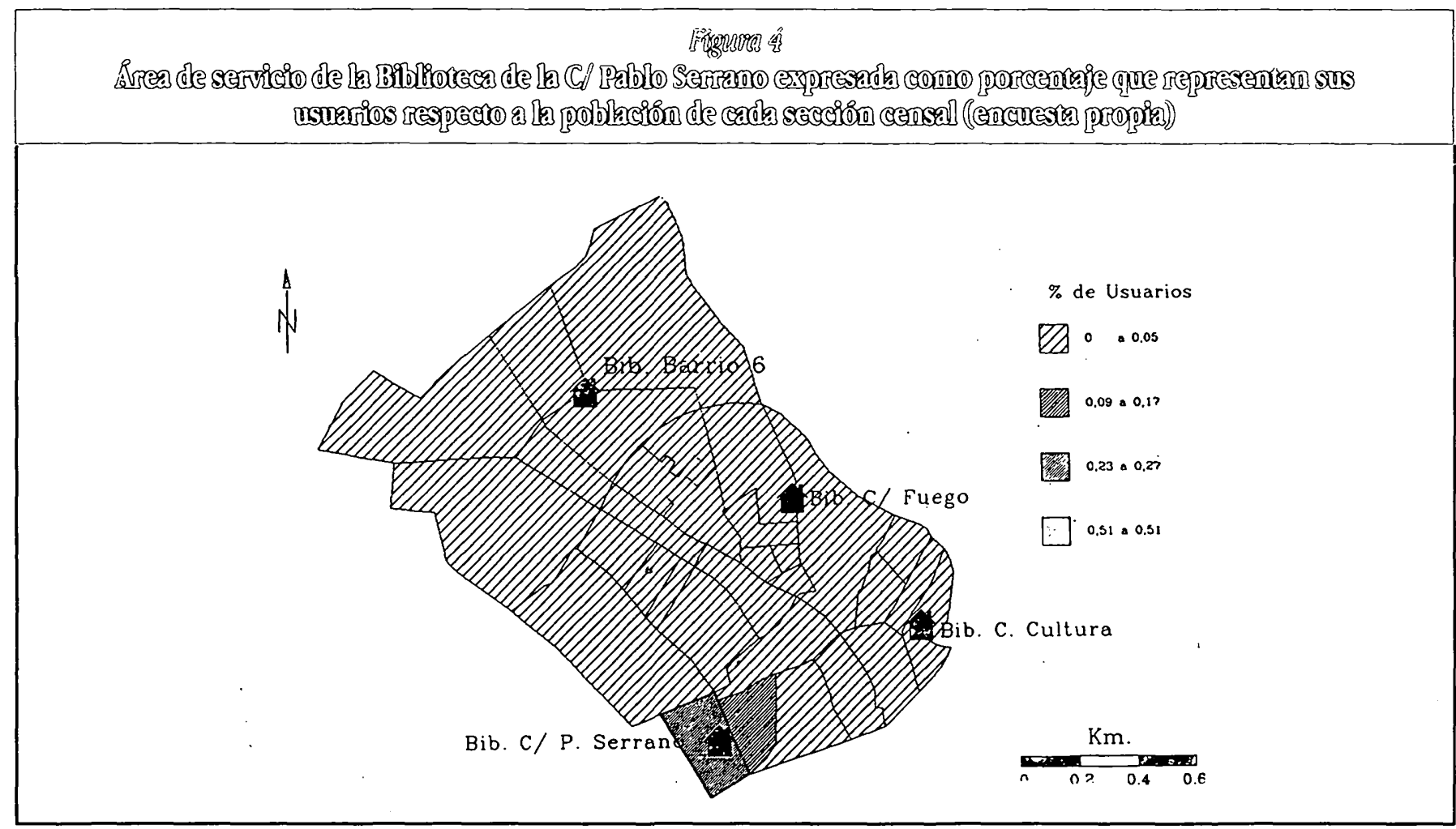

Fuente: Elaboración propia.

Irignara 5

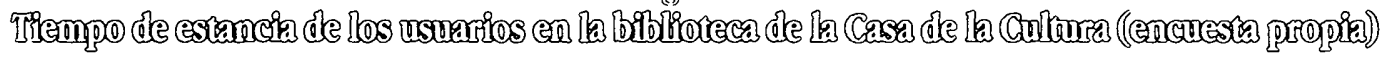
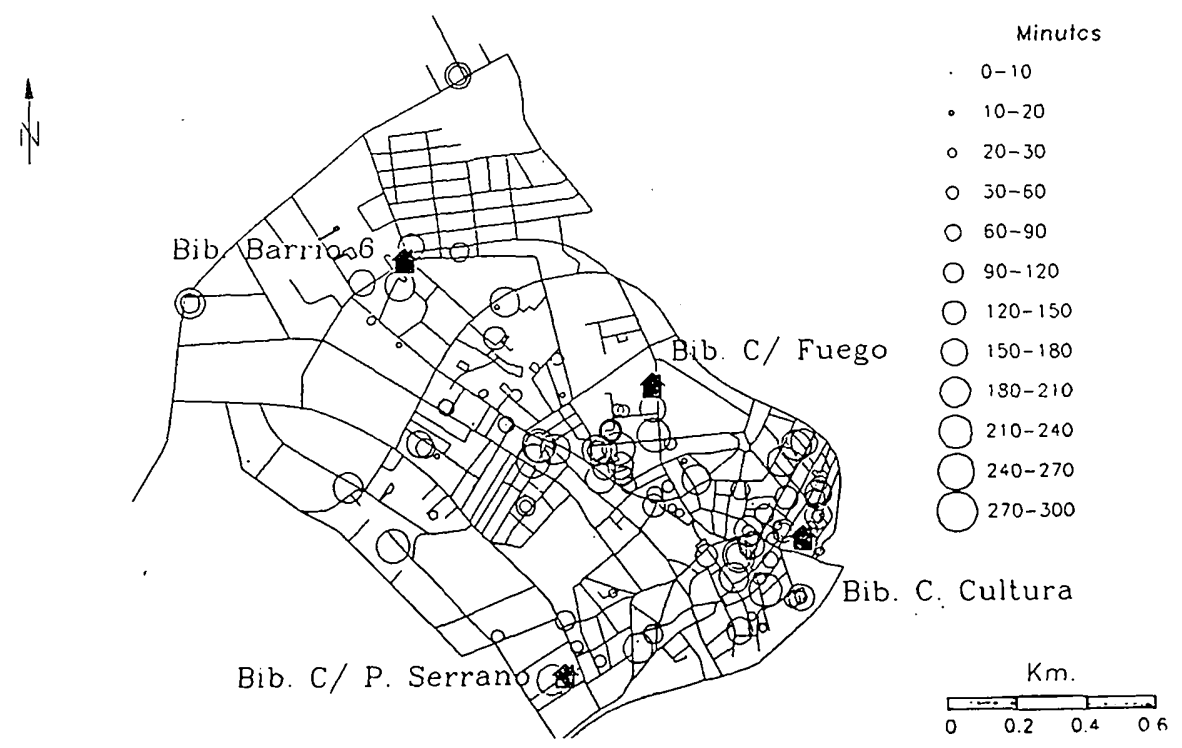

Fuente: Elaboración propia.

el área de servicio de una biblioteca mucho más modesta, la lectura y una valoración del alcance territorial de los beneficios sita en la calle Pablo Serrano (figura 4) posibilita una plástica derivados de cada uno de estos puntos de servicio público. 
No obstante, el poder de los SIG en el manejo de información espacial hace posible análisis más refinados. Ante la tesitura de evaluar de forma más precisa el beneficio social en las diferentes zonas de la ciudad podría pensarse en adoptar indicadores que cuantificasen la magnitud individualmente $y$ procediesen a su agregación por zonas. En el marketing comercial un interés central reside en conocer, por ejemplo, qué volumen de las compras se realiza en cada uno de los establecimientos de la empresa. Análogamente, en un servicio como el que comientamos sería pertinente adoptar indicadores de la cuantía y tipo de uso, por ejemplo los préstamos, las consultas, las visitas o las horas de permanencia en cada biblioteca; y todo ello registrado para cada individuo al objeto de poder elaborar análisis a la escala territorial que se desee. La disponibilidad de esa información en un SIG abre un horizonte espectacular a la evaluación de los beneficios gènerados individual y colectivamente. Por ejemplo, en la figura 5 se presenta el tiempo de estancia, según la encuesta, para los usuarios de una de las bibliotecas. Dicha información, ora para cada punto de servicio, ora para el conjunto de ellos, es susceptible de ser agregada de nuevo al objeto de facilitar un mensaje de notable expresividad e interés para los decisores: el grado de uso que por zonas se realiza, bien de forma absoluta (figura 6), bien relativa a un segmento relevante de la demanda, como exhibe la figura 7.

Irigentace (6)

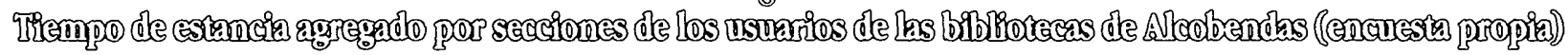

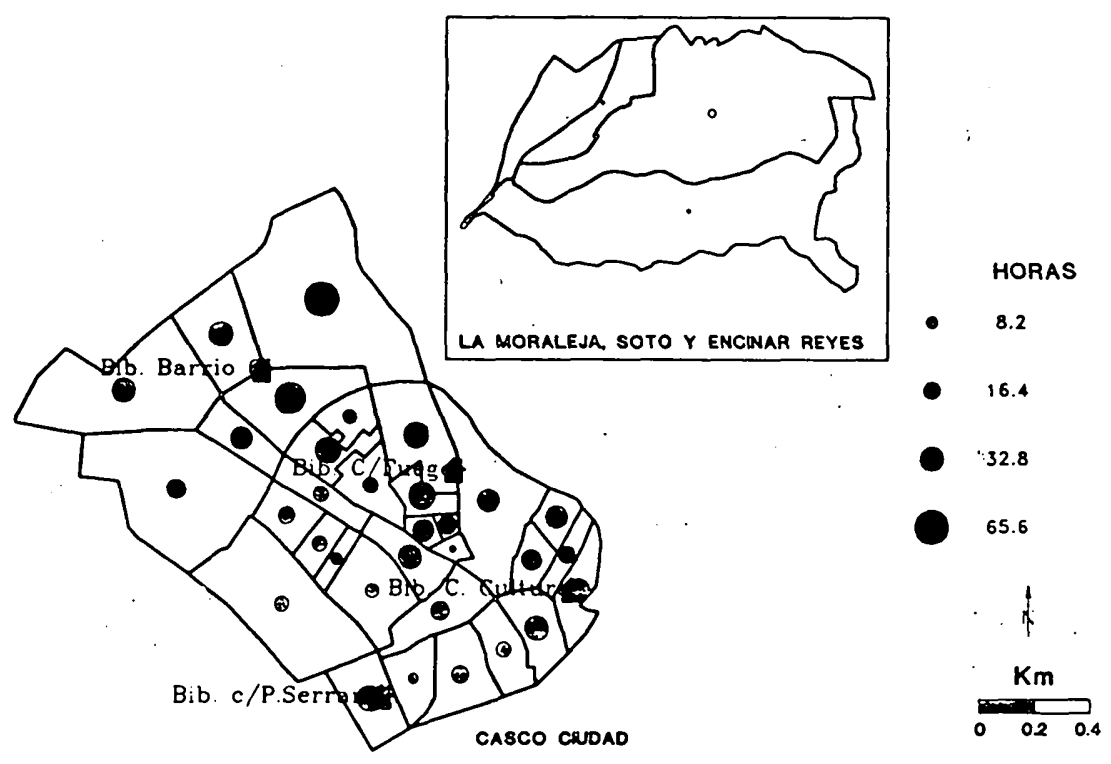

Fuente: Elaboración propia.

\subsection{Hacia un examen del servicio desde la justicia socio-espacial}

La valoración de un servicio público como el aquí estudiado, en el que cabe presumir una intencionalidad en la dotación por parte del poder y los responsables municipales y una elegibilidad por parte de los destinatarios, suscita la necesidad de un análisis que desvele de forma suficiente los logros de los mismos. Dicho de forma más concreta, el problema estriba en comprobar en qué medida ciertos objetivos de las políicas son alcanzados. La mecánica tradicional de los procesos de decisión pública local conllevaba una explicitación escasa de dichos objetivos, por lo que, a efectos evaluadores, es obligado recurrir a hipótesis o presunciones sobre los mismos. Esta última es la situación de este trabajo en el que se recurrirá a algunos principios clásicos en la bibliografía para mostrar las posibilidades analíticas de la metodología ensayada.

Los conceptos de equidad, eficiencia y efectividad han estado en la base del debate teórico sobre la provisión pública de servicios (vid. por ejemplo Savas, 1978; Bramley, 1986). La aproximación que desde la Geografía y otras disciplinas afines se ha hecho a la cuestión ha permitido, por un lado, fundamentar una conceptualización de los mismos y de la noción clave de justicia en términos territoriales (vid. HaRveY, 1973; ReYNAUd, 1981; Pirue, 1983; BoYNe y Powell, 1991; HaY, 1995) y, por otro, disenar medidas específicas de los mismos que enfatizan e incorporan el efecto desnivelador inherente a la distribución territorial de las dotaciones y de los destinatarios de los servicios (vid. 


\section{Fitereng?}

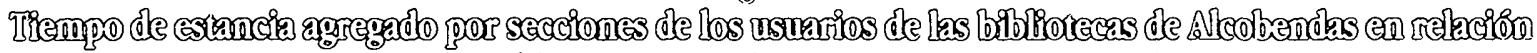

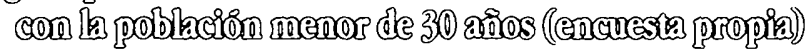

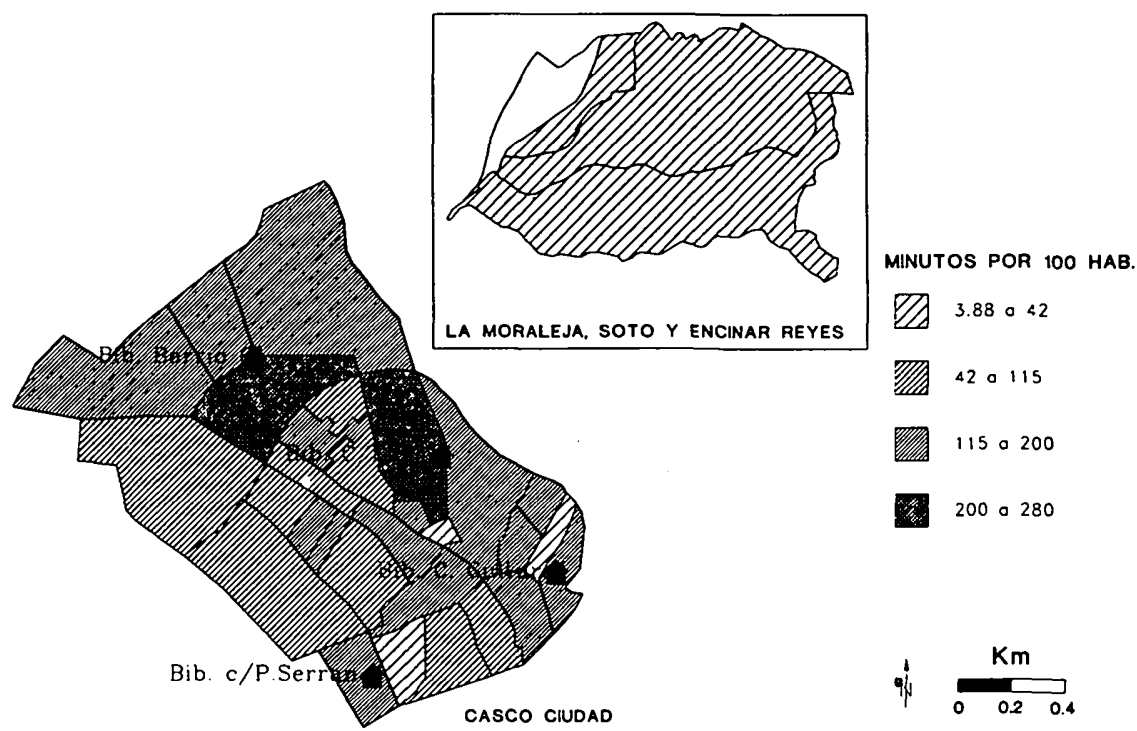

Fuente: Elaboración propia

Morrill y Symons, 1977; Mulligan, 1991; Truelove, 1993; MarSh y SCHILING, 1994).

Analíticamente el punto de partida ha de tomar en cuenta las consideraciones que justifican la orientación de los servicios públicos locales para el consumo: por un lado, satisfacer las necesidades de la demanda potencial y, por otro, redistribuir socio-espacialmente unos recursos a través de las "utilidades" 0 beneficios aportados por dichos servicios públicos. Los anteriores enunciados permiten recurir a dos de las operacionalizaciones geográficas del concepto de justicia (Hay, 1995, págs. 505-6) relevantes para nuestro interés: por un lado, la igualdad espacial, una de cuyas interpretaciones estipularía el logro de una igualdad o similitud en los resultados per capita entre las diversas zonas; por otro, la justicia territorial, que confiere una atención sustantiva a la necesidad social (variable por zonas), y avistaría a una distribución proporcional a dicha necesidad.

Desarrollaremos algo más los precedentes conceptos en sus implicaciones para la indagación empírica. La aplicación, por una parte, del principio de igualdad espacial supone admitir que las diferencias sociales en la demanda de bibliotecas no deben tomarse en cuenta, o lo que es lo mismo, que son irrelevantes. Tal razonamiento equivaldría a pensar que la demanda/necesidad es similar a lo largo de la población por lo que, consecuentemente, el servicio debería propiciar la consecución de logros o resultados proporcionales a los efectivos demográficos de las diferentes zonas. La aplicación, por otra parte, del principio de justicia te- rritorial al campo de la provisión de servicios públicos implicaría adoptar, como premisa, que la necesidad cultural es diferente socio-espacialmente y que la política al respecto debería ser discriminatoria positivamente. En términos simples, ello conllevaría favorecer a los que poseen más necesidad cultural.

A la hora de ejecutar un análisis concreto bajo las anteriores premisas se requiere operacionalizar los conceptos de logros/resultados por una parte y de necesidad por otra. En lo concerniente a esta última se trataría de averiguar la necesidad social espacializada de bibliotecas. De los cuatro significados del concepto de necesidad establecidos por BraDSHAW (1974) resultarían otras tantas formas de medirla que abocarían a conclusiones seguramente dispares. A partir de las premisas asumidas en este trabajo parece más pertinente entender que, teniendo en mente la meta social de incrementar el nivel de formación, el principio de justicia territorial reclamańa que las utilidades derivadas de ese servicio público beneficiasen más proporcionalmente a aquéllos que tienen un menor nivel cultural (i.e., más necesidad o carencia), rasgo que, como es sabido, suele acompanar a las capas socialmente más bajas. En virtud de ello la especificación espacial de la necesidad debería apoyarse en indicadores socio-demográficos, más o menos refinados, de la misma, respecto a los cuales confrontar y valorar los recursos aportados o logros obtenidos.

En lo concerniente a los resultados o logros cabe insistir en que la utilidad social de una oferta como la bibliotecaria debe materializarse en actos de servicio/uso satisfactorios y ello signi- 
fica que se tiene que producir una confluencia espacio-temporal entre los que prestan y los que demandan dicho servicio. Desde la perspectiva geográfica el asunto se ha contemplado sobre todo como un problema de accesibilidad espacial, por cuanto la oferta y la población están localizadas y es preciso desplazarse hasta aquélla para lograr esa satisfacción. A partir de ahí, una importante y fructífera línea de investigación ha avistado el estudio de la desigualdad o justicia espacial de las dotaciones públicas mediante indicadores de accesibilidad o de oportunidades espaciales (por ejemplo, MLADENKA y HiLl, 1977). Caben, sin embargo, otras formas de abordar la cuestión, como diferenció PINCH (1985) y se ha postulado anteriormente, en la medida en que el uso real es una manera bastante significativa de transcribir las utilidades/beneficios, no potenciales o esperables, como hacen los indicadores de accesibilidad, sino observados.

En este sentido, una satisfacción igualitaria de la misma se debería materializar en que el uso constatado de los servicios tuviese una proporcionalidad con los efectivos demográficos. Es decir, en aquellas zonas donde hay más usuarios potenciales (por ejemplo población) cabría esperar asimismo una mayor utilización. La verificación cuantitativa de ese principio requeriría un cierto grado de paralelismo o correlación positiva entre ambos hechos. Desde el otro principio manejado, la justicia territorial, la hipótesis estribaría en comprobar el grado en que el uso generado fuese más abundante proporcionalmente en las zonas donde el nivel socio-cultural fuese más bajo. La lógica conllevaría a una relación inversa entre ambos hechos.

Llegados a este punto surgen algunos problemas, no secundarios, en cualquier investigación, tales como especificar las variables y seleccionar unas determinadas unidades espaciales para la medición, en la medida en que no sólo resultan discutibles y refutables, sino también condicionantes de los resultados y conclusiones. En todo caso, y asumiendo las limitaciones inherentes, se han adoptado como indicadores de la demanda potencial las siguientes variables (referidas a 1991):

- Población total.

- Población menor de 15 años.

- Población entre 15 y 29 años.

- Población escolar.

Y como indicadores de nivel cultural y social las siguientes:

- Número de analfabetos.

- Población con sólo estudios primarios.

- Población con estudios medios.

- Población con estudios universitarios.

- Parados.

\begin{tabular}{|c|c|c|}
\hline \multicolumn{3}{|c|}{ 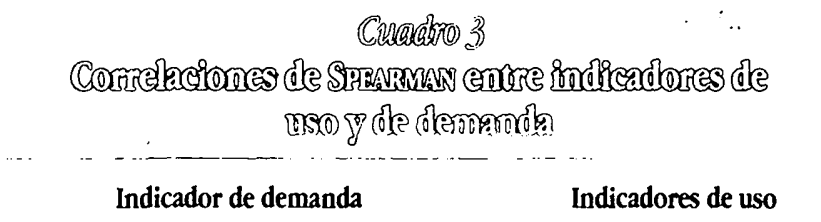 } \\
\hline . & N. usuarios & $\begin{array}{c}\text { Tiempo de } \\
\text { estancia }\end{array}$ \\
\hline \multicolumn{3}{|l|}{ Demanda Potencial } \\
\hline Población total & 0.329 & $0.347^{\circ}$ \\
\hline Población de 0 a 14 años & 0.351 • & $0.347^{\circ}$ \\
\hline Población de 15 a 29 años & 0.155 & 0.171 \\
\hline Población escolar & 0.228 & 0.237 \\
\hline \multicolumn{3}{|l|}{ Tilulación } \\
\hline Analfabetos & $0.342 *$ & $0.347^{\star}$ \\
\hline \multicolumn{3}{|l|}{ Nivel de estudios } \\
\hline Sólo estudios primarios & $0.600 *$ & $0.595 * 0$ \\
\hline Estudios medios & 0.067 & 0.045 \\
\hline Estudios universitarios & -0.022 & -0.051 \\
\hline \multicolumn{3}{|l|}{ Actividad } \\
\hline Parados & $0.493^{*}$ & $0.509^{\prime}$ \\
\hline \multicolumn{3}{|l|}{ Categoria Profesional } \\
\hline Subaltemos & $0.565 *$ & $0.569^{* *}$ \\
\hline Operarios & $0.536 *$ & $0.569 * 0$ \\
\hline \multicolumn{3}{|l|}{ Profesión } \\
\hline Profesionales, técnicos y similares & 0.065 & 0.082 \\
\hline Pers. directivo admón. pública y empresas & -0.112 & -0.207 \\
\hline
\end{tabular}

- Sería significativo al nivel del $5 \%$.

- Seria significativo al nivel del $1 \%$.

Fuente: Elaboración propia.

- Subalternos.

- Operarios.

- Profesionales.

- Personal directivo.

A los efectos de comprobar el grado de correspondencia entre necesidad y uso, por razones prácticas se decidió adoptar la partición censal (secciones) como unidad espacial que ofrecía un suficiente nivel de desagregación intraurbana. En consecuencia, y habida cuenta de que la forma de la división espacial condiciona los resultados estadísticos, debe recordarse que éstos serán válidos en la medida en que sea aceptable dicha partición. Finalmente, como técnica para comprobar las similitudes espaciales entre la demanda/necesidad así definida y el uso, se recurrió a la correlación de SPEARMAin, tras desechar la de PEAR. SON por no cumplirse en muchos casos los requisitos impuestos por dicho coeficiente. Los resultados obtenidos se presentan en el cuadro 3. 
La observación de los indices permite establecer algunas conclusiones:

A) El uso real inducido por la oferta existente muestra una correspondencia medio-baja con dos indicadores de demanda global: la población total por un lado y la población infantil por otro. Independientemente pues de las posibles disfuncionalidades espaciales, la dotación consigue efectivamente que en las zonas más pobladas y con más niños haya un mayor uso del servicio. La duda importante, que no es posible dilucidar del análisis realizado, estriba en si esos resultados podrían ser mejores con otra distribución espacial de la oferta.

B) Donde se alcanzan correlaciones más elevadas es entre los indicadores de uso y los asociados con anecesidad cultural", esto es, con variables representativas de bajo nivel cultural y bajo status social. Este hecho permite una interpretación en el sentido de que la dotación municipal efectivamente traduce una discriminación positiva al conseguir favorecer más (superior utilización) a aquellas zonas de mayor necesidad.

\section{Conclusión}

La labor de evaluar reviste una notable complejidad intrínseca y, en el terreno concreto de los servicios públicos, su aplicación presenta todavía unos importantes frentes para la innovación y experimentación metodológicas. La multiplicidad de facetas relevantes a considerar concitan la conjunción de perspectivas varias, a menudo compartimentadas en disciplinas académicas distintas, pero complementarias. Desde una de ellas, la geográfica, en las últimas décadas se están proponiendo cuestiones y facetas que permiten enriquecer notoriamente el proceso de decisiones públicas al proporcionar una información tratada con unos instrumentos analíticns propios. En trabajos previos uno de los autores ha realizado ensayos metodológicos, no sólo de carácter doctrinal (MoReno, 1987; 1993; 1995; MoReno y Bosque, 1993), sino empírico (MORENo, 1992) sobre cómo integrar la perspectiva geográfica en el análisis, planificación y gestión de servicios públicos para la población. En el presente artículo se han desvelado algunas cuestiones empíricas relativas a la provisión de un servicio municipal típico, el de bibliotecas, tales como los niveles de eficiencia de los distintos equipamientos, los perfiles socio-demográficos de los usuarios de las bibliotecas, o la medición, desde el punto de vista de la equidad, de los resultados espaciales del servicio. No obstante, el acento ha recaído sobre todo en un objetivo metodológico: ilustrar algunas de las posibilidades del enfoque geográfico que, al enfatizar la dimensión espacial de los indicadores de uso, los perfiles de los usuarios, o los indicadores de equidad, confiere una nueva y expresiva luz a la información idónea para la gestión y planificación de este tipo de servicios. En la consecución de una rentabilidad social óptima, una eficiencia en la gestión o cualesquiera otros objetivos de las políticas públicas sobre servicios, la disponibilidad de unos datos tan detallados espacialmente como los aquí aportados, supone indudablemente un nuevo valor añadido, bajo la forma de un mejor conocimiento, que permite a los responsables y destinatarios sustentar ulteriores actuaciones "o profundizar en las evaluaciones, sea cual fuere el modelo adoptado para éstas. Bastaría recordar, adicionalmente, la fuerte expansión que los SIG están adquiriendo en el campo del geomarketing comercial, o el "redescubrimiento" de la importancia de la localización (de la oferta y de la demanda), para atisbar uno de los frentes desde el que se puede mejorar las decisiones públicas en este campo.

\footnotetext{
- Profesor Titular de Geografia Humana. Dpto. de Geografia. Universidad Autónoma de Madrid.

- Diplomada en Documentación y Licenciada en Ciencias de la Educación.

${ }^{1}$ El presente estudio ha sido realizado dentro del proyecto PB92-0150 de la Dirección General de Investigación Cientifica y Técnica. Ministerio de Educación y Ciencia.

Agradecemos la colaboración desinteresada del personal del Servicio de Bibliotecas y del Dpto. de Investigación Social y Evaluación de Políticas Municipales del Ayuntamiento de Alcobendas.

: En diversas fases del estudio han colaborado los siguientes geógrafos: Julia Espada, Nuria Gómez, Carmen Gutiérrez, Carmen Herráiz, Pilar Herráiz, Pilar Jarque y Ricardo Martinez.
}

- Se consideran aquí sólo las cuatro bibliotecas existentes, excluyendo el servicio de bibliobús por su especial naturaleza.

\footnotetext{
' Los mapas, al recoger sólo el ámbito de Alcobendas (total o parcial), excluyen siempre a los usuarios provenientes de otros municipios. Puede resultar interesante reseñar que ese hecho, conocido en la bibliografia anglosajona como free riders, es patente sobre todo respecto al municipio de San Sebastián de los Reyes por estar en su casco urbano adyacente.

Véase, al respecto, Clouclells y MoNMONIER (1995) quienes han pergeñado, bajo la forma de guión ilustrativo, la secuencia de cómo insertar la información geográfica en un caso de decisión sobre la localización de un vertedero, con miras a informar a los agentes sociales involucrados.
} 


\section{Bibliografia}

BALlART: X. (1992), ¿Cómo evaluar programas y servicios puiblicos? Apraximación sistemátiu. vestudius de caso. Madrid, Ministerio para las Administraciones Públicas (INAP).

BARRIL DOSSET, R. (1985), Hacia un diagnóstico de los servicios locales por un sistema de indicadores: especial referencia a los indicadores de productividad (s.l.), Instituto de Estudios de Administración Local. .

BENNETT, R. (1980), The geography of public finance. Londres, Methuen.

BoYNe, G. y Powell, M. (1991), -Territorial justice: a review of theory and evidence. Political Geograpby, 10, pp. 263-281.

BradSHaw, J. (1974), The concept of social need, Ekistics, 37, pp. 184187.

Bramiley, G. (1986), •Defining equal standards in local public services, Urban Studies, 23, pp. 391-412.

BRYSON, J. (1992), Técnicas de gestión para bibliotecas y centros de información. Madrid, Fundación Germán Sánchez Ruipérez.

CaLjins, (1991), .GIS and public policy., en Magure, D., GoOdChILD, M. y RHind, D. (ed.): Geograpbical information systemis. Harlow, Longman, vol. 2, pp. 233-245.

COUCLELS, H. y MonMonIER, M.S. (1995), .Using SUSS to resolve NIMBY: How spatial understanding support systems can help with the *Not in my back yard. syndrome, Geographical Systems, 2, 2, pp. 83-102.

CROMPTON, J.L. y LAMB, Ch.W. (1986), Marketing government and social services. New York, John Wiley and Sons.

CuRT1S, S. (1989), The geograpby of public welfare provision. Londres, Routledge.

DelGaDO, A. (1993), Análisis de mercado y su aplicación en bibliotecas públicas', Boletin de ANABAD, XLIII, 1, pp. 43-50.

Duarte BaRRIONuEvo, M. (1995), Indicadores como instrumento de evaluación de los servicios bibliotecarios: 1. Aspectos metodológicos, Boletin de ANABAD, XIV, 1, pp. 95-106.

GRIMmEAU, J.P. y RoELANDTS, M. (1995), •Géomarketing: une presentation à travers huit ans de pratique, Reune Belge de Géographie, 119, pp. 289-306.

GRIMSHAW, D.J. (1994), Bringing geographical information systems into business. Harlow, Longman.

HARVEY, D. (1973), Social justice and the city. Londres, Edward Amold (Trad. esp.: Ur. banismo y desigualdad social. Madrid, Siglo XXI, 1977).

HAY, A. (1995), Concepts of equity, fairness and justice in geographical studies. Transactions of Institute of British Geographers, 20, pp. 500-508.

HENDRIKSON, K. et al. (1994), . Normas para bibliotecas universitarias: evaluación de la eficacia, Boletin de ANABAD, XIIV, 3, pp. 193-222.

KOTLR, Ph. Y ANDREASEN, A. (1987), Strategic marketing for non-profit onganizations Englewood Cliffs, Prentice Hall.

KOTIER, Ph. y ROBERTO, E.L. (1992), Marketing social. Estrategias para cambiar la conducla publica. Madrid, Díaz de Santos.

LANCASTER, F.W. (1988), If you want to evaluate your library ... Champaign, Ill., University of Illinois, Graduate School of Library and Information Science.

__(1990), Evaluation as a management tool, Public Libraries, sept-oct., pp. 289-294.

LINEBERRY, R. (1977), Equality and urban policy. The distribution of municipal public services. Beverly Hills, Sage
LONSDALE, R. y EVYEDI, G. (1984), Rural public services. International comparisons. Boulder, Westriew Press.

MARSH, M. y SCHILING, D. (1994), Equity measurement in facility location analysis: A review and framework, European Joumal of Operational Research, 74, pp. 1-17.

MASSAM, B. (1975), Location and space in social administration. Londres, E. Amold.

(1993), The right place. Shared responsability and the location of public facilities. Harlow, Longman.

MEYER, D. (1986), Services publics et redistribution du revenu. Neuchatel, EDES.

MLADENKA, K. y HILL, K. (1977), The distribution of benefits in an urban environment. Parks and libraries in Houston, Urban Affairs Quaterly, 13, 1, pp. 73-94

MONNIER, E. (1992), Eualuation de liaction des poutoirs publics. París, Economica, 2.? ed.

MoreNo, A. (1987), •Planificación espacial de equipamientos públicos: El diagnóstico, $X$ Congreso Nacional de Geografia, Zaragoza, A. G. E., 1987, pp. 357-366.

(1991), Una panorámica de las perspectivas teóricas sobre los servicios colectivos, Boletin de la Asociación de Geógrafos Españoles, 12, pp. 33-58.

(1992), los sistemas de información geográfica en la planificación de servicios municipales, $1^{7}$. Congreso. Los sistemas de información geográfica en la gestión territorial. Madrid, pp. 377-391.

(1993), •Evaluación de políticas y gestión de servicios locales con sistemas de información geográfica., Tecnimap-93, III Jomadas sobre Tecnologias de la Información para la Modermización de las Administraciones Püblicas. Granada, MAP, etc., vol. l, pp. 379-388.

(1995), •Planificación y gestión de servicios a la población descle la perspectiva territorial: algunas propuestas metodológicas, Boletin de la Asociación de Geógrafos Esparioles, 20, pp. 115-134.

_. $y$ BosQuE, J. (1993), •Diseño de un sistema de información geográfica para la gestión de servicios sociales, $2 .{ }^{\circ}$ Congreso. Los sistemas de información geográfica en el umbral del s. XXI. Madrid, pp. 213-222.

_ y ESCOLANO, S. (1992), El comercio y los servicios para la producción y el consumo. Madrid, Sintesis.

MORRILl, R. y SimONS, J. (1977), •Efficiency and equity aspects of optimum location, Geograpbical Analysis, IX, pp. 215-225.

MuLugav, G. (1981), Equality measures and facility location., Papers in Regional Science, 70, 4, pp. 345-365.

OJIAMBO, J.B. (1994), Application of marketing principles and techniques to libraries and information centres", Library Review, 43, 2, pp. 46-51.

PATTON, C. y SAWICKI, D. (1986), Basic methods of policy analysis and planning. Englewood Cliffs, Prentice Hall.

PINCH, S. (1985), Cities and services. The geography of collective consumption. Londres, Routledge and Kegan Paul.

PIRIE, G.H. (1983), -On spatial justice, Environment and Planning $A, 15$, pp. $465-473$.

REYNAUD, A. (1981), Société, espace et justice. Paris, PUF.

SAVAS, E. (1978), . On equity in providing public services, Management Science, 24, 8, pp. $800-808$. 
SMiTH, D. (1977), Human geograpby: A welfare approacb. Londres, Amold (Trad. esp.: Geografia bumana. Barcelona, Oikos tau, 1980).

SuBIRATS, J. (1989), Evaluación de politicas priblicas y eficacia de la administración. Madrid, INAP.

Trürove, M. (1993), -Measurement of spatial equity, Environment and Planning $C$, $11, \mathrm{pp} .19-34$.
WaLSH, K.; ClaRKE, M. y STEWART, J. (1989), Marketing in local govemment. Harlow, Longman.

W/HTाEнAl, T. (1992), Quality in library and information service: A review, Library Management, 13, 5, pp. 23-35.

WORRAL, L. (ed.) (1991), Spatial analysis and spatial policy using geograpbic informations systemis. Londres, Belhaven. 

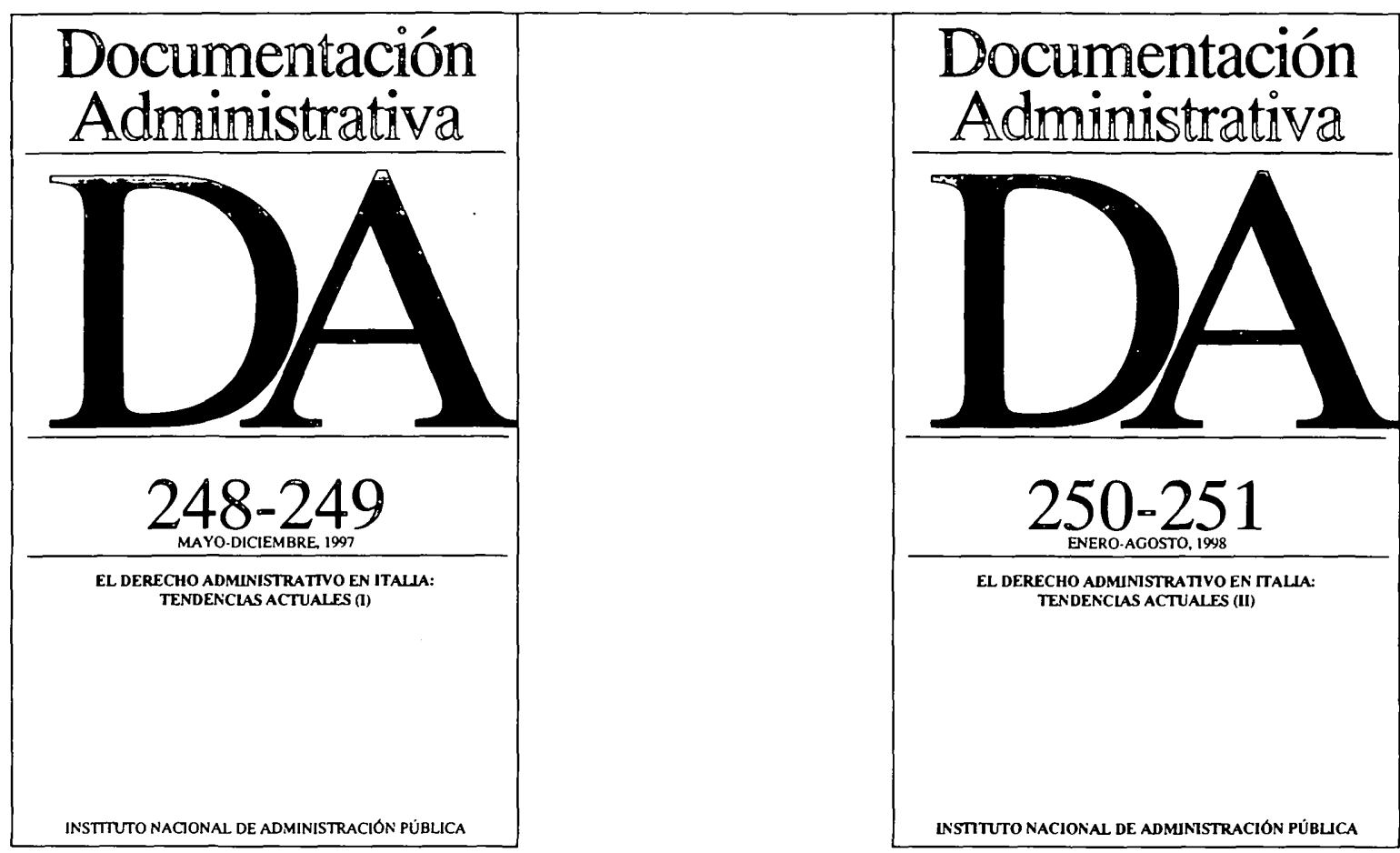

EL DERECHO ADMINISTRATIVO EN TTALAA TENDENCLAS ACTUALES (II)

Publicación cuatrimestral del Instituto Nacional de Administración Pública, especializada en Derecho Administrativo y Organización y Gestión de las Administraciones Públicas.

Aparecida en 1958, la característica más destacada de su actual etapa es la dedicación monográfica de cada número a una cuestión específica, que se analiza desde diferentes puntos de vista por acreditadas firmas de España y otros países.

\section{CONSEJO DE REDACCIÓN}

Presidente: Alejandro Nieto García. Vocales: José Javier Abad Pérez, Óscar Alzaga Villamil, Manuel Aragón Reyes, Enrique Argullol Murgadas, Gaspar Ariño Ortiz, Miguel Beltrán Villalva, Andrés de Blas Guerrero, José Manuel Castells Arteche, Ínigo Cavero Lataillade, Rafael Gómez-Ferrer Morant, Francisco González Navarro, Jesús González Pérez, Luis Morell Ocaña, Sebastián Martín-Retortillo Baquer, José Ramón Parada Vázquez, Jesús Prieto de Pedro, Eduardo Roca Roca, Ángel Rodríguez García, Juan Alfonso Santamaría Pastor, Gumersindo Trujillo Fernández.

\section{Director}

\section{Luciano Parejo Alfonso}

\section{Edita:}

MINISTERIO DE ADMINISTRACIONES PÚBLICAS

Instituto Nacional de Administración Pública

ISSN: 0012-4494

NIPO: 329-97-004-5

Depósito legal: M. $581-1958$

Imprime: Solana e Hijos, A.G., S.A.

San Alfonso, 26. 28917 Madrid

\section{Suscripciones y Administración:}

Instituto Nacional de Administración Pública Publicaciones Periódicas Atocha, 106. 28012 Madrid Teléfono: 3493104

\section{Precios:}

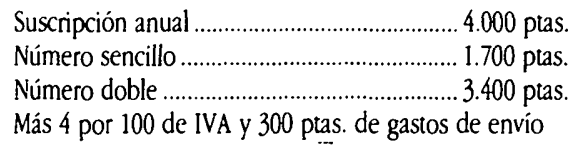

